\title{
is Research Square \\ The prognostic value of KRAS mutation in locally advanced rectal cancer.
}

\section{Palash Asawa}

Allegheny General Hospital

\section{Veli Bakalov}

Allegheny General Hospital

\section{Pragnan Kancharla}

Allegheny General Hospital

\section{Stephen Abel}

Allegheny General Hospital

\section{Zena Chahine}

Markey Cancer Center

\section{Dulabh K. Monga}

Allegheny General Hospital

\section{Alexander V. Kirichenko}

Allegheny General Hospital

Rodney E. Wegner ( $\square$ Rodney.wegner@ahn.org )

Allegheny General Hospital

\section{Research Article}

Keywords: Locally advanced rectal cancer, KRAS mutation, prognostic value, colorectal cancers, gene mutations

Posted Date: March 7th, 2022

DOI: https://doi.org/10.21203/rs.3.rs-1413877/v1

License: (c) (1) This work is licensed under a Creative Commons Attribution 4.0 International License. Read Full License 


\section{Abstract}

\section{Background}

The prognostic value of the KRAS proto-oncogene mutation in colorectal cancer has been debated. Herein, we analyzed the National Cancer Database (NCDB) to assess the role of KRAS mutation as a prognostic marker in patients with locally advanced rectal cancer (LARC).

\section{Methods}

We identified LARC patients treated with neoadjuvant chemoradiation from 2004-2015 excluding those with stage I/IV disease and unknown KRAS status. Multivariable logistic regression identified variables associated with KRAS positivity. Propensity adjusted univariable and multivariable analyses identified predictors of survival.

\section{Results}

Of the 784 eligible patients, 506 were KRAS negative (KRAS-) and 278 were KRAS positive (KRAS+). Median survival was 63.6 months and 76.3 months for KRAS+ and KRAS- patients respectively, with propensity adjusted 3 and 5 -year survival of $79.9 \%$ vs. $83.6 \%$ and $56.7 \%$ vs $61.9 \%$ respectively (HR $1.56, p$ 1.074-2.272). Male sex, no insurance, and KRAS+ disease was associated with poorer survival on unadjusted and propensity adjusted multivariable analyses.

\section{Conclusions}

Our analysis of KRAS+ LARC suggest that KRAS+ disease is associated with poorer overall survival. Given the inherent limitations of retrospective data, prospective validation is warranted.

\section{Introduction}

Colorectal cancers (CRC) are commonly occurring malignancies and are the fourth most common cancer worldwide. Treatment is directed after careful consideration of primary tumor, regional lymph node involvement, and the presence of distant metastasis. Surgery, radiotherapy, and chemotherapy are three major treatment options available for rectal cancer. Historically, neoadjuvant chemoradiotherapy (CRT) has been utilized in the neoadjuvant setting for locally advanced rectal cancer (LARC). Important prognostic factors for overall survival include the extent of the disease (TNM stage), lymphatic and vascular invasion, pathological grade, circumferential resection margin, and the type of surgery. ${ }^{1}$

The use of biomarkers to help more accurately prognosticate for patients with rectal cancer is gaining popularity. About $35-45 \%$ of patients diagnosed with LARC have an underlying KRAS mutation. ${ }^{2,3}$ The KRAS protein is a member of the RAS family and is a membrane-anchored guanosine triphosphate/guanosine diphosphate (GTP/GDP)-binding protein. ${ }^{4}$ The KRAS is responsible for intracellular signal transduction mainly from the epidermal growth factor receptor (EGFR). The transition 
from inactive KRAS (GDP-bound) to the active state (GTP-bound) leads to downstream activations of more than 20 effectors, including Raf, phosphatidylinositol 3-kinase (PI3K), and Ral guanine nucleotidedissociation stimulator (RALGDS), and regulates proliferation, survival, and differentiation. Mutations in KRAS result in persistent accumulation of the active GTP-bound KRAS protein and leads to activation of downstream pro-proliferative signaling pathways and associated with resistance to anti-EGFR therapy. ${ }^{5}$

The prognostic value of the KRAS proto-oncogene mutation in colorectal cancer has been debated. Herein, we analyzed the National Cancer Database (NCDB) to assess the role of KRAS mutation as a prognostic marker in patients with locally advanced rectal cancer (LARC).

\section{Methods}

For our analysis, we used the National Cancer Database (NCDB). The database comprises approximately $70 \%$ of cancer cases in the United States from over 1500 hospitals accredited by the Commission on Cancer. ${ }^{6}$ For our analysis we queried the database to identify rectal cancer patients diagnosed between the years 2004-2015. A complete CONSORT diagram is illustrated in Fig. 1. Patients with known KRAS status, stage II and III, known resection of the rectum, radiotherapy, chemotherapy, and patients with known pathological stage were included in our study.

Descriptive statistics were reported for pertinent variables and Chi-square test was used to compare demographic, socioeconomic, clinical, and treatment characteristics between the KRAS positive and negative patients. A bivariate logistic regression model was used to determine the association between independent variables of interest and KRAS status. Overall survival (OS) was calculated from the date of diagnosis to the date of last contact or death using Kaplan Meier curves to present the cumulative probability of survival, and log-rank statistics to assess statistical significance between groups. Adjusted hazard ratios (HR) and 95\% confidence interval $(\mathrm{Cl})$ are reported, with $a=0.05$ used to indicate statistical significance. Propensity score analysis was used to account for indication bias caused by a lack of randomization. ${ }^{7}$ Propensity scores were calculated by multivariable logistic regression to provide a score reflecting the conditional probability for KRAS status and were used to create a pseudo population with the identical distribution of the confounding variables in each KRAS group. We used Cox proportional hazard model adjusting for propensity score. Statistical analysis was performed using SPSS version 23.

\section{Results}

\section{Baseline characteristics}

A total of 784 patients were selected for final analysis and among them, 506 (64.5\%) were KRAS negative and the remaining KRAS positive. Baseline demographic characteristics are shown in Table 1. The median age of the patients was 56 with a male predominance (57.3). Most patients had poorly differentiated $(70.3 \%)$ and clinical stage III (62.4\%) disease. Most of the patients received radiation therapy with a dose between 50.4-54 Gy (62.8\%). The KRAS mutation was more likely to be found in 
patients treated at academic research programs (OR 1.510, 95\% Cl 1.1109 to 2.0770) (Table 2). Female gender was also associated with mildly increased risk of KRAS mutation; however, this association was not significant (OR $1.289795 \mathrm{Cl} 0.9603$ to 1.7322). 
Table 1

Baseline characteristics

Number of patients

(\%)

All patients 784

Demographics

Sex

Male

Female

Age

Median / Mean

$<60$

$>60$

Race

White

African American

Other/unknown

Comorbidity score

0

2

Insurance

Private

Not insured

Government
Disease characteristics

Clinical T stage

449 (57.27)

335 (42.73)

T1/T2

49 (6.25)

T3

631

(80.48)

$\mathrm{T} 4$

90

(11.48)

8 (1.0)

Clinical T size

$<2 \mathrm{~cm}$

113

(14.41)

$2-5 \mathrm{~cm}$

$286(36$

$.48)$

$>5 \mathrm{~cm}$

293

(37.37)

Unknown

92

(11.73)

Clinical N stage

NO

288

(36.73)

N1

365

(46.56)

N2

115

(14.67)

Unknown

16 (2.04)

Clinical stage

434 (55.36)

Stage II

295

(37.6)

46 (5.87)

Stage III

489

(62.4)

Grade 


\begin{tabular}{|c|c|c|c|}
\hline & $\begin{array}{l}\text { Number of patients } \\
(\%)\end{array}$ & & \\
\hline Other & $10(1.28)$ & Well differentiated & $\begin{array}{l}83 \\
(10.59)\end{array}$ \\
\hline Treatment facility type & & Moderately differentiated & $64(8.16)$ \\
\hline $\begin{array}{l}\text { Comprehensive cancer } \\
\text { program/other }\end{array}$ & $298(38.01)$ & Poorly differentiated & $\begin{array}{l}549 \\
(70.03)\end{array}$ \\
\hline Academic/research program & $443(56.51)$ & Unknown/Other & $\begin{array}{l}88 \\
(11.22)\end{array}$ \\
\hline Community cancer program & $43(5.48)$ & Microsatellite instability & \\
\hline Treatment facility location & & Negative (stable) & $\begin{array}{l}703 \\
(89.67)\end{array}$ \\
\hline Metro counties & $587(74.87)$ & Positive (instable) & $\begin{array}{l}81 \\
(10.33)\end{array}$ \\
\hline Urban counties & $150(19.13)$ & $\begin{array}{l}\text { Pathologic Complete } \\
\text { Response }\end{array}$ & \\
\hline Rural/other counties & $47(5.99)$ & pCR negative & $\begin{array}{l}740 \\
(94.4)\end{array}$ \\
\hline Income, US dollars & & pCR positive & $44(5.6)$ \\
\hline$<48,000$ & $480(63.2)$ & Treatment characteristics & \\
\hline$>48,000$ & $279(36.8)$ & Radiation dose, Gy & \\
\hline $\begin{array}{l}\text { Distance to treatment facility, } \\
\text { miles }\end{array}$ & & Median Gy & 50.4 \\
\hline$<10$ & $350(44.64)$ & $<50.4$ & $\begin{array}{l}249 \\
(31.76)\end{array}$ \\
\hline$>10$ & $434(55.36)$ & $>50.4$ and $<54$ & $\begin{array}{l}492 \\
(62.76)\end{array}$ \\
\hline Year of diagnosis & & $>54$ & $43(5.48)$ \\
\hline $2010-2011$ & $186(23.72)$ & & \\
\hline $2012-2013$ & 277 (35.33) & & \\
\hline $2014-2015$ & $321(40.94)$ & & \\
\hline
\end{tabular}


Table 2

Comparative Baseline Characteristics for KRAS Status

KRAS ( $) \quad$ KRAS (+) OR $(95 \% \mathrm{Cl})$

$p$

All patients

Demographics

Sex

Male

Female

Age

\section{Median / Mean}

$<60$

$>60$

Race

White

African American

Other/unknown

Comorbidity score

0

1

2

\section{Insurance}

Private

Not insured

Pivate
506

278

\begin{tabular}{llll|}
\hline 301 & $\begin{array}{l}148 \\
(59.49)\end{array}$ & 1 & \\
\hline 205 & $(53.24)$ & & 0.0909 \\
$(40.51)$ & $(40.76)$ & $\begin{array}{l}1.2897 \\
(0.9603 \text { to } 1.7322)\end{array}$ & \\
\hline
\end{tabular}

$58 / 51.01 \quad 55 / 54.71$

$\begin{array}{lll}295(58.3) & 159 & 1 \\ & (57.19) & \end{array}$

211

(41.70)

119

(42.81)

1.0464

(0.7782 to 1.4070$)$
427

(84.39)

$52(10.28)$

237

(85.25)

0.6804

$27(5.34) \quad 15(5.40)$

(0.5481 to 1.4805 )

1.0009
$(0.5221$ to 1.9190$)$

0.9977

$\begin{array}{lll}394 & 218 & 1 \\ (77.87) & (78.42) & \end{array}$

$\begin{array}{lll}87(17.19) \quad 49(17.63) & 1.0179 \\ & & (0.6911 \text { to } 1.4993)\end{array}$

0.9283

25 (4.94) $11(3.96)$

0.7952

0.5374

(0.3839 to 1.6472 )

0.5374

278

(54.94)

27 (5.34)

\section{6}

(56.12)

$19(6.83)$
1.2540

(0.6754 to 2.3284) 


\begin{tabular}{|c|c|c|c|c|}
\hline & $\operatorname{KRAS}(-)$ & KRAS (+) & OR (95\% Cl) & $p$ \\
\hline Government & $\begin{array}{l}193 \\
(38.14)\end{array}$ & $\begin{array}{l}101 \\
(36.33)\end{array}$ & $\begin{array}{l}0.9326 \\
(0.6837 \text { to } 1.2721)\end{array}$ & 0.6594 \\
\hline Other & $8(1.58)$ & $2(0.78)$ & $\begin{array}{l}0.4455 \\
(0.0934 \text { to } 2.1241)\end{array}$ & 0.3103 \\
\hline \multicolumn{5}{|l|}{ Treatment facility type } \\
\hline $\begin{array}{l}\text { Comprehensive cancer } \\
\text { program/other }\end{array}$ & $209(41.3)$ & $89(32.01)$ & 1 & \\
\hline Academic/research program & $\begin{array}{l}269 \\
(53.16)\end{array}$ & $\begin{array}{l}174 \\
(62.59)\end{array}$ & $\begin{array}{l}1.510 \\
\text { (1.1109 to } 2.0770)\end{array}$ & 0.008 \\
\hline Community cancer program & $28(5.53)$ & $15(5.4)$ & $\begin{array}{l}1.2580 \\
\text { (0.6409 to } 2.4694)\end{array}$ & 0.5047 \\
\hline \multicolumn{5}{|l|}{ Treatment facility location } \\
\hline Metro counties & $\begin{array}{l}388 \\
(76.68)\end{array}$ & $\begin{array}{l}199 \\
(71.58)\end{array}$ & 1 & \\
\hline Urban counties & 87 (17.19) & $63(22.66)$ & $\begin{array}{l}1.4119 \\
\text { (0.9786 to } 2.0369)\end{array}$ & 0.0651 \\
\hline Rural/other counties & $31(6.13)$ & $16(5.76)$ & $\begin{array}{l}1.0063 \\
(0.5375 \text { to } 1.8840)\end{array}$ & 0.9843 \\
\hline \multicolumn{5}{|l|}{ Income, US dollars } \\
\hline$<48,000$ & $\begin{array}{l}306 \\
(62.57)\end{array}$ & $174(64.4)$ & 1 & \\
\hline$>48,000$ & $183(37.4)$ & $96(35.6)$ & $\begin{array}{l}0.9226 \\
(0.6771 \text { to } 1.2569)\end{array}$ & 0.6094 \\
\hline \multicolumn{5}{|l|}{$\begin{array}{l}\text { Distance to treatment facility, } \\
\text { miles }\end{array}$} \\
\hline$<10$ & $\begin{array}{l}233 \\
(46.05)\end{array}$ & $\begin{array}{l}117 \\
(42.09)\end{array}$ & 1 & \\
\hline$>10$ & $\begin{array}{l}273 \\
(53.95)\end{array}$ & $\begin{array}{l}161 \\
(57.91)\end{array}$ & $\begin{array}{l}1.1744 \\
(0.8741 \text { to } 1.5780)\end{array}$ & 0.2860 \\
\hline \multicolumn{5}{|l|}{ Year of diagnosis } \\
\hline $2010-2011$ & $\begin{array}{l}123 \\
(24.31)\end{array}$ & $63(22.66)$ & 1 & \\
\hline $2012-2013$ & $\begin{array}{l}182 \\
(35.97)\end{array}$ & 95 (34.17) & $\begin{array}{l}1.0191 \\
(0.6885 \text { to } 1.5084)\end{array}$ & 0.9247 \\
\hline 2014-2015 & $\begin{array}{l}201 \\
(39.72)\end{array}$ & $\begin{array}{l}120 \\
(43.17)\end{array}$ & $\begin{array}{l}1.1656 \\
(0.7982 \text { to } 1.7021)\end{array}$ & 0.4276 \\
\hline
\end{tabular}




\section{KRAS (-) $\quad$ KRAS (+) OR $(95 \% \mathrm{Cl})$}

\section{Disease characteristics}

\section{Clinical T stage}

$\mathrm{T} 1 / \mathrm{T} 2$

T3

T4

Unknown

\section{Clinical T size}

$<2 \mathrm{~cm}$

$2-5 \mathrm{~cm}$

$>5 \mathrm{~cm}$

Unknown

\section{Clinical N stage}

NO

N1

N2

Unknown

\section{Clinical stage}

Stage II

Stage III

\section{Grade}

Well differentiated

Moderately differentiated

$31(6.13) \quad 18(6.47) \quad 1$

$\begin{array}{lll}412 & 219 & 0.9155\end{array}$

(81.42)

(78.78)

(0.5007 to 1.6739$)$

0.7742

$53(10.47) \quad 37(13.31) \quad 1.2023$

(0.5872 to 2.4619$)$

$6(1.2)$

$2(0.7)$

0.5741

(0.1046 to 3.1502$)$

0.5229

0.6144

0.8516

(0.6596 to 1.6553$)$

$75(14.82) \quad 38(13.67)$

\begin{tabular}{|c|c|c|c|}
\hline $\begin{array}{l}187 \\
(36.96)\end{array}$ & $99(35.61)$ & $\begin{array}{l}1.0449 \\
(0.6596 \text { to } 1.6553)\end{array}$ & 0.8516 \\
\hline $\begin{array}{l}188 \\
(37.15)\end{array}$ & $\begin{array}{l}105 \\
(37.77)\end{array}$ & $\begin{array}{l}1.1023 \\
(0.6976 \text { to } 1.7419)\end{array}$ & 0.6764 \\
\hline
\end{tabular}

$56(11.07) \quad 36(12.9) \quad 1.2688$

0.4150

(0.7158 to 2.2489$)$

0.4150

$\begin{array}{lll}192 & 96(34.53) & 1 \\ (37.94) & \end{array}$

$\begin{array}{llll}229 & 136 & 1.1878 & 0.2981 \\ (45.26) & (48.92) & (0.8590 \text { to } 1.6425) & \end{array}$

$\begin{array}{lll}77(15.22) \quad 38(13.67) & 0.9870 \\ & & (0.6235 \text { to } 1.5625)\end{array}$

$\begin{array}{lll}7(1.4) \quad 5(1.8) \quad & 1.4286 \\ & & (0.4418 \text { to } 4.6191)\end{array}$

0.5514

$195(38.5) \quad 100(36.0) \quad 1$

$311(61.5) \quad 178(64.0) \quad 1.1161$

(0.8240 to 1.5117$)$

0.4780

$55(10.87) \quad 28(10.07) \quad 1$

$42(8.3) \quad 22(7.91) \quad 1.0289$

(0.5172 to 2.0469$)$

0.9353 


\begin{tabular}{|c|c|c|c|c|}
\hline & KRAS (-) & KRAS (+) & OR $(95 \% \mathrm{Cl})$ & $p$ \\
\hline Poorly differentiated & $\begin{array}{l}355 \\
(70.16)\end{array}$ & $\begin{array}{l}194 \\
(69.78)\end{array}$ & $\begin{array}{l}1.0734 \\
(0.6593 \text { to } 1.7478)\end{array}$ & 0.7757 \\
\hline Unknown/Other & $54(10.67)$ & $34(12.23)$ & $\begin{array}{l}1.2368 \\
(0.6617 \text { to } 2.3116)\end{array}$ & 0.5054 \\
\hline \multicolumn{5}{|c|}{ Microsatellite instability } \\
\hline Negative (stable) & $\begin{array}{l}454 \\
(89.72)\end{array}$ & $\begin{array}{l}249 \\
(89.57)\end{array}$ & 1 & \\
\hline Positive (instable) & $52(10.28)$ & $29(10.43)$ & $\begin{array}{l}1.0168 \\
(0.6293 \text { to } 1.6430)\end{array}$ & 0.9456 \\
\hline \multicolumn{5}{|c|}{ Pathologic Complete Response } \\
\hline pCR negative & $477(94.3)$ & $263(94.6)$ & 1 & \\
\hline pCR positive & $29(5.7)$ & $15(5.4)$ & $\begin{array}{l}0.9381 \\
(0.4940 \text { to } 1.7814)\end{array}$ & 0.8452 \\
\hline \multicolumn{5}{|c|}{ Treatment characteristics } \\
\hline \multicolumn{5}{|l|}{ Radiation dose, Gy } \\
\hline Median Gy & 50.4 & 50.4 & & \\
\hline$<50.4$ & $\begin{array}{l}159 \\
(31.42)\end{array}$ & $90(32.37)$ & 1 & \\
\hline$>50.4$ and $<54$ & $\begin{array}{l}316 \\
(62.45)\end{array}$ & $\begin{array}{l}176 \\
(63.31)\end{array}$ & $\begin{array}{l}0.9840 \\
(0.7163 \text { to } 1.3517)\end{array}$ & 0.9205 \\
\hline$>54$ & $31(6.13)$ & $12(4.32)$ & $\begin{array}{l}0.6839 \\
(0.3346 \text { to } 1.3976)\end{array}$ & 0.2974 \\
\hline
\end{tabular}

Survival analysis

Median survival for KRAS-positive patients was 63.6 months and 76.3 months for KRAS-negative patients (Fig. 2). On a propensity score, matched 3-year survival of KRAS negative patients was $83.6 \%$ and $79.9 \%$ for KRAS positive patients; 5 -year survival of KRAS negative patients was $61.9 \%$ and $56.7 \%$ of KRAS negative patients $(p=0.0195)$. On multivariable analysis year of diagnosis of $2014-2015$, KRAS positivity was associated with an increased risk of death, while female gender was associated with decreased risk of death. The significance of the above-mentioned variables was preserved after adjustment to propensity score. (Table 3 ) 
Table 3

Multivariable Cox Proportional Hazards Models for Overall Survival.

Without Propensity Score

Hazard of death with $95.0 \%$

$\mathrm{Cl}$
Propensity Score Adjusted

p- $\quad$ Hazard of death with $95.0 \%$

$\begin{array}{ll}\text { Hazard of death with } 95.0 \% & \begin{array}{l}\mathrm{p} \text { - } \\ \text { value }\end{array}\end{array}$

\section{Gender}

Male

Reference

Reference

Female

$0.651(0.458-0.927)$

0.017

$0.627(0.439-0.896)$

0.010

Insurance

Private

Reference

Reference

Not insured

0.494(0.262-0.934)

0.030

$0.475(0.251-0.901)$

0.023

Government

0.843(0.433-1.641)

0.614

0.923 (0.487-1.749)

0.806

Year of

diagnosis

2010-2011

Reference

Reference

2012-2013

1.056 (0.720-1.549)

0.779

1.044 (0.719-1.516)

0.822

2014-2015

2.133(1.225-3.713)

0.007

$1.845(1.072-3.175)$

0.027

KRAS status

KRAS negative Reference

Reference

KRAS positive

$1.641(1.178-2.286)$

0.003

$1.489(1.078-2.058)$

0.016

\section{Discussion}

In our study, we utilized the NCDB database to understand the role of KRAS mutation in 784 LARC patients. The KRAS mutation in LARC patients was associated with poorer median survival (63.6 months) as compared to wild-type KRAS (76.3 months). It was also associated with poorer $3(79.9 \%)$ and 5-year (56.7\%) survival as compared to KRAS negative LARC patients. Over $35-45 \%$ of patients diagnosed with LARC have an underlying KRAS mutation, which is like the representation of KRAS-positive patients in our analyzed population (35.5\%). ${ }^{2}$ The reported prognostic value of KRAS mutations in rectal cancer is conflicting. While several studies have indicated no association of KRAS mutations with treatment responsiveness and long-term survival ${ }^{8-12}$, some studies have demonstrated that KRAS mutation is associated with an increased risk of relapse and death in patients with colorectal cancer and tend to have high rates of resistance to chemotherapy. ${ }^{13,14}$ 
The RASCAL study, a meta-analysis of 2721 patients with CRC found an association of KRAS mutations with increased risk of death. ${ }^{14}$ Similarly, Lièvre et al. studied the effect of anti-EGFR targeted monoclonal antibody (cetuximab) on $30 \mathrm{mCRC}$ patients screened for KRAS and found a significant association between a KRAS mutation and failure of response to the anti-EGFR treatment. Those who responded to the treatment had no KRAS mutation in their tumor. ${ }^{15}$ In a larger series of 89 patients, Lièvre et al. again showed KRAS mutation had a statistically significant decrease in progression-free survival and overall survival in patients with metastatic CRC treated with Cetuximab. ${ }^{16}$

Peng et al. studied 70 LARC patients of which 25 had a documented KRAS mutation. Like our study, these patients all underwent preoperative irradiation of $50 \mathrm{~Gy}$ and had a total resection of their primary tumor. The study also looked at other oncogenic mutations such as PIK3CA, NRAS, and BRAF and showed patients with an oncogenic mutation had a statistically significantly worse 3-year disease-free survival, however, had similar OS. Those with KRAS mutation not only exhibited worse disease-free survival than patients with wild-type KRAS but also worse OS. ${ }^{17}$

Conflicting studies argue that while KRAS mutations confer resistance to targeted treatment and may thus affect tumor progression, it may not be a reliable prognostic factor. The CALGB randomized control trial studied 508 patients with stage III colon cancer for disease-free survival. Patients were divided into two treatment groups (5-fluorouracil, leucovorin with or without irinotecan) and were followed for 6 years. They found no significant difference in disease-free, recurrence-free, and overall survival between KRAS wild-type and KRAS-mutated patients. The authors believe that the results of previous trials showing a significant association between KRAS mutation and OS is likely because the studies included smaller patient populations and are therefore inaccurate. When the population is larger (such as their 508 patients), it becomes more difficult to prove a prognostic value of KRAS. ${ }^{18}$ Similarly, Lee et al. retrospectively studied 108 patients with LARC treated with preoperative CRT and curative surgery with a follow-up time of 34 months. ${ }^{19}$ They found no statistical significance in the recurrence-free survival and overall survival at 3 years between KRAS wild-type and KRAS-mutated patients. The authors attributed previous significant outcomes to patients being treated with anti-EGFR-targeted therapies. Patients in this study received leucovorin and 5-FU and thus KRAS mutation status is not a prognostic factor in their analysis. Differences inpatient population, treatment modality, and sample sizes may all be factors that explain the inconsistency between study data on whether KRAS is a good prognostic indicator.

Implications of KRAS as a prognostic value may play a role in improving treatment modalities. There is substantial evidence to support the predictive value of KRAS mutations in the setting of anti-EGFR treatment in metastatic CRC. This is seen in trials such as the PRIME, CRYSTAL, and OPUS experience where adding anti-EGFR medication showed improved outcomes with patients who have WT KRAS and no improvement of survival for those with a mutated KRAS. ${ }^{20-22}$ However, studies to assess response to treatment of LARC are limited, and thus larger studies are warranted. Analyzing KRAS mutations may help identify high-risk patients who may require more aggressive therapeutic modalities. Moreover, 
molecular testing of RAS mutations is essential to further tailor anti-EGFR therapy for patients with LARC being considered for anti-EGFR therapy.

The large population sample and robust statistical analysis confer high statistical power to this study; however, several factors limit the interpretation of the results. This includes the possibility of selection bias given the retrospective nature of the NCDB database. The NCDB database is based on diagnostic codes and thus there is a potential for incomplete or inaccurate coding. In addition, the NCDB database does not provide information on important aspects like ECOG status, smoking history, type of chemotherapy, number of cycles of chemotherapy provided, and dose-limiting toxicities, all of which could impact treatment response and survival.

\section{Conclusion}

Our study validates the notion that KRAS is a good prognosticator in LARC patients through the NCDB database, which to our knowledge has not been done before. We focused on patients with LARC as data regarding the prognostic significance of KRAS is more limited in this population.

\section{Declarations}

Funding: This research did not receive any specific grant from funding agencies in the public, commercial, or not-for-profit sectors

Conflict of Interest: No author present on this article has any conflicts of interest.

Prior presentations: The abstract was published online by ASCO as part of the proceedings of the annual ASCO meeting, 2019

Ethical approval: Institutional review board approval was obtained for the study

Authors Contributions:

Palash Asawa: Conceptualization, Methodology, Writing - Original Draft

Veli Bakalov: Conceptualization, Methodology, Formal analysis, Investigation, Writing - Original Draft, Review and Editing, Visualization

Zena Chahine: Conceptualization, Methodology, Writing - Review and Editing

Stephen Abel: Conceptualization, Methodology, Writing - Review and Editing

Pragnan Kancharla: Conceptualization, Methodology, Writing - Review and Editing

Dulabh K. Monga: Conceptualization, Methodology, Writing - Review and Editing 
Alexander V. Kirichenko: Conceptualization, Methodology, Writing - Review and Editing

Rodney Wegner: Conceptualization, Methodology, Formal analysis, Investigation, Software Resources, Writing - Original Draft, Review and Editing, Visualization, Project Administration

Acknowledgements: None

Data Statement: Authors VB and RW had full access to all the data in the study. We take full responsibility for the integrity of the data and the accuracy of the analysis as well as sharing the data with any interested investigators.

\section{References}

1. Li Y, Wang J, Ma X, et al. A Review of Neoadjuvant Chemoradiotherapy for Locally Advanced Rectal Cancer. Int J Biol Sci 2016;12(8):1022-31. (In eng). DOI: 10.7150/ijbs.15438.

2. von Moos R, Koeberle D, Schacher $S$, et al. Neoadjuvant radiotherapy combined with capecitabine and sorafenib in patients with advanced KRAS-mutated rectal cancer: A phase I/II trial (SAKK 41/08). Eur J Cancer 2018;89:82-89. (In eng). DOI: 10.1016/j.ejca.2017.11.005.

3. Abdul-Jalil KI, Sheehan KM, Toomey S, et al. The frequencies and clinical implications of mutations in 33 kinase-related genes in locally advanced rectal cancer: a pilot study. Ann Surg Oncol 2014;21 (8):2642-9. (In eng). DOI: 10.1245/s10434-014-3658-x.

4. Malumbres M, Barbacid M. RAS oncogenes: the first 30 years. Nat Rev Cancer 2003;3(6):459-65. (In eng). DOI: 10.1038/nrc1097.

5. Schubbert S, Shannon K, Bollag G. Hyperactive Ras in developmental disorders and cancer. Nat Rev Cancer 2007;7(4):295-308. (In eng). DOI: 10.1038/nrc2109.

6. Winchester DP, Stewart AK, Bura C, Jones RS. The National Cancer Data Base: a clinical surveillance and quality improvement tool. J Surg Oncol 2004;85(1):1-3. (In eng). DOI: 10.1002/jso.10320.

7. D'Agostino RB, Jr. Propensity score methods for bias reduction in the comparison of a treatment to a non-randomized control group. Stat Med 1998;17(19):2265-81. (In eng). DOI: 10.1002/(sici)10970258(19981015)17:19<2265::aid-sim918>3.0.co;2-b.

8. Bengala $C$, Bettelli S, Bertolini F, et al. Prognostic role of EGFR gene copy number and KRAS mutation in patients with locally advanced rectal cancer treated with preoperative chemoradiotherapy. $\mathrm{Br} \mathrm{J}$ Cancer 2010;103(7):1019-24. (In eng). DOI: 10.1038/sj.bjc.6605853.

9. Garcia-Aguilar J, Chen Z, Smith DD, et al. Identification of a biomarker profile associated with resistance to neoadjuvant chemoradiation therapy in rectal cancer. Ann Surg 2011;254(3):486-92; discussion 492-3. (In eng). DOI: 10.1097/SLA.0b013e31822b8cfa.

10. Kim SY, Hong YS, Kim DY, et al. Preoperative chemoradiation with cetuximab, irinotecan, and capecitabine in patients with locally advanced resectable rectal cancer: a multicenter Phase II study. Int J Radiat Oncol Biol Phys 2011;81(3):677-83. (In eng). DOI: 10.1016/j.jijobp.2010.06.035. 
11. Erben $P$, Ströbel $P$, Horisberger $K$, et al. KRAS and BRAF mutations and PTEN expression do not predict efficacy of cetuximab-based chemoradiotherapy in locally advanced rectal cancer. Int $\mathrm{J}$ Radiat Oncol Biol Phys 2011;81(4):1032-8. (In eng). DOI: 10.1016/j.jrobp.2010.06.043.

12. Hu-Lieskovan S, Vallbohmer D, Zhang W, et al. EGF61 polymorphism predicts complete pathologic response to cetuximab-based chemoradiation independent of KRAS status in locally advanced rectal cancer patients. Clin Cancer Res 2011;17(15):5161-9. (In eng). DOI: 10.1158/1078-0432.Ccr-102666.

13. Andreyev HJ, Norman AR, Cunningham D, Oates JR, Clarke PA. Kirsten ras mutations in patients with colorectal cancer: the multicenter "RASCAL" study. J Natl Cancer Inst 1998;90(9):675-84. (In eng). DOI: $10.1093 /$ jnci/90.9.675.

14. Andreyev HJ, Norman AR, Cunningham D, et al. Kirsten ras mutations in patients with colorectal cancer: the 'RASCAL II' study. Br J Cancer 2001;85(5):692-6. (In eng). DOI: 10.1054/bjoc.2001.1964.

15. Lièvre $A$, Bachet JB, Le Corre $D$, et al. KRAS mutation status is predictive of response to cetuximab therapy in colorectal cancer. Cancer Res 2006;66(8):3992-5. (In eng). DOI: 10.1158/0008-5472.Can06-0191.

16. Lièvre $A$, Bachet JB, Boige $V$, et al. KRAS mutations as an independent prognostic factor in patients with advanced colorectal cancer treated with cetuximab. J Clin Oncol 2008;26(3):374-9. (In eng). DOI: $10.1200 /$ jco.2007.12.5906.

17. Peng J, Lin J, Qiu M, et al. Oncogene mutation profile predicts tumor regression and survival in locally advanced rectal cancer patients treated with preoperative chemoradiotherapy and radical surgery. Tumour Biol 2017;39(7):1010428317709638. (In eng). DOI: 10.1177/1010428317709638.

18. Ogino S, Meyerhardt JA, Irahara N, et al. KRAS mutation in stage III colon cancer and clinical outcome following intergroup trial CALGB 89803. Clin Cancer Res 2009;15(23):7322-9. (In eng). DOI: 10.1158/1078-0432.Ccr-09-1570.

19. Lee JW, Lee JH, Shim BY, et al. KRAS Mutation Status Is Not a Predictor for Tumor Response and Survival in Rectal Cancer Patients Who Received Preoperative Radiotherapy With 5-Fluoropyrimidine Followed by Curative Surgery. Medicine (Baltimore) 2015;94(31):e1284. (In eng). DOI: 10.1097/md.0000000000001284.

20. Douillard JY, Siena S, Cassidy J, et al. Final results from PRIME: randomized phase III study of panitumumab with FOLFOX4 for first-line treatment of metastatic colorectal cancer. Ann Oncol 2014;25(7):1346-1355. (In eng). DOI: 10.1093/annonc/mdu141.

21. Köhne $\mathrm{CH}$, Poston G, Folprecht $\mathrm{G}$, et al. FOLFIRI plus cetuximab in patients with liver-limited or nonliver-limited RAS wild-type metastatic colorectal cancer: A retrospective subgroup analysis of the CRYSTAL study. Eur J Surg Oncol 2016;42(10):1540-7. (In eng). DOI: 10.1016/j.ejso.2016.05.038.

22. Bokemeyer C, Bondarenko I, Hartmann JT, et al. Efficacy according to biomarker status of cetuximab plus FOLFOX-4 as first-line treatment for metastatic colorectal cancer: the OPUS study. Ann Oncol 2011;22(7):1535-1546. (In eng). DOI: 10.1093/annonc/mdq632. 


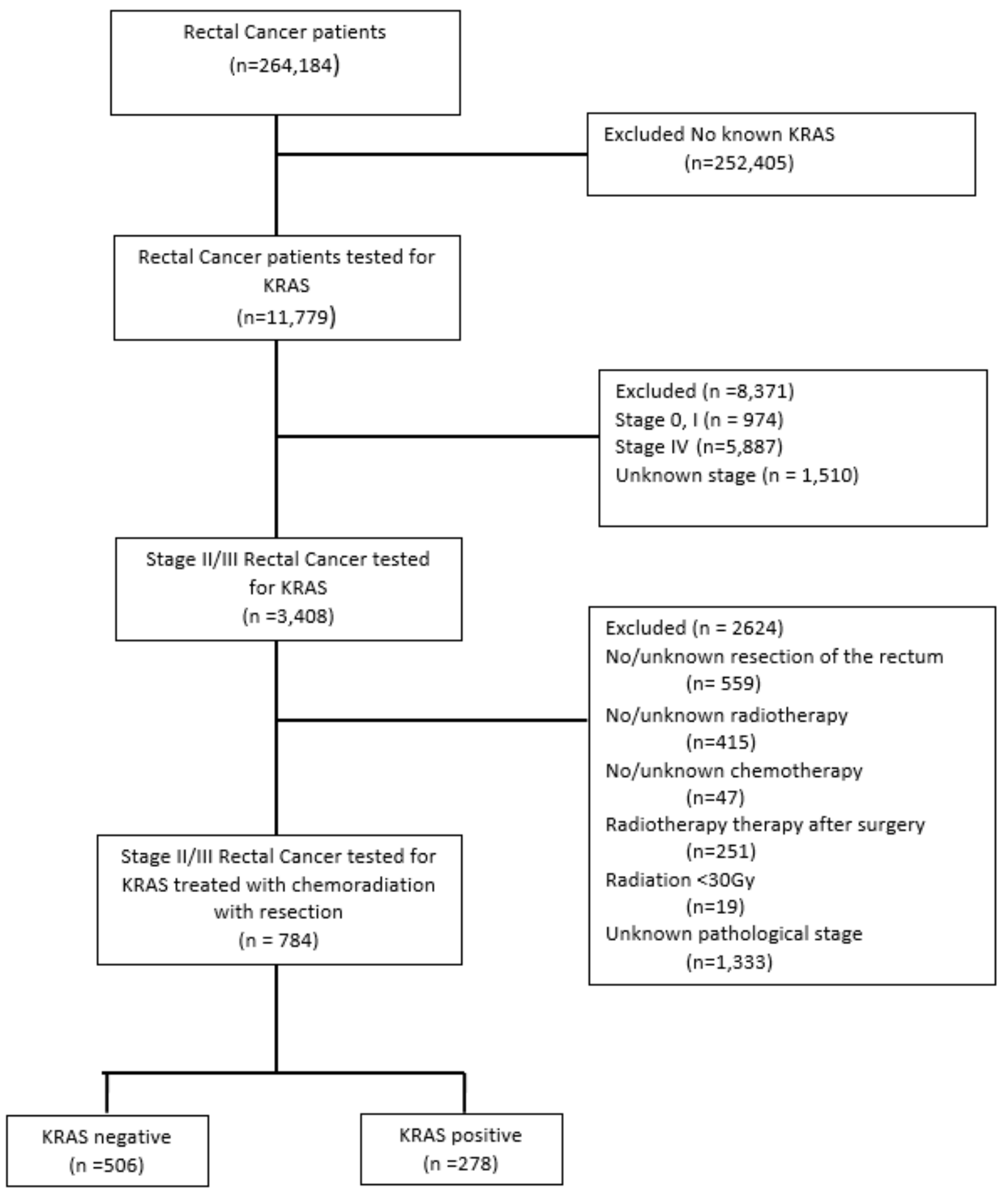

Figure 1

CONSORT diagram 


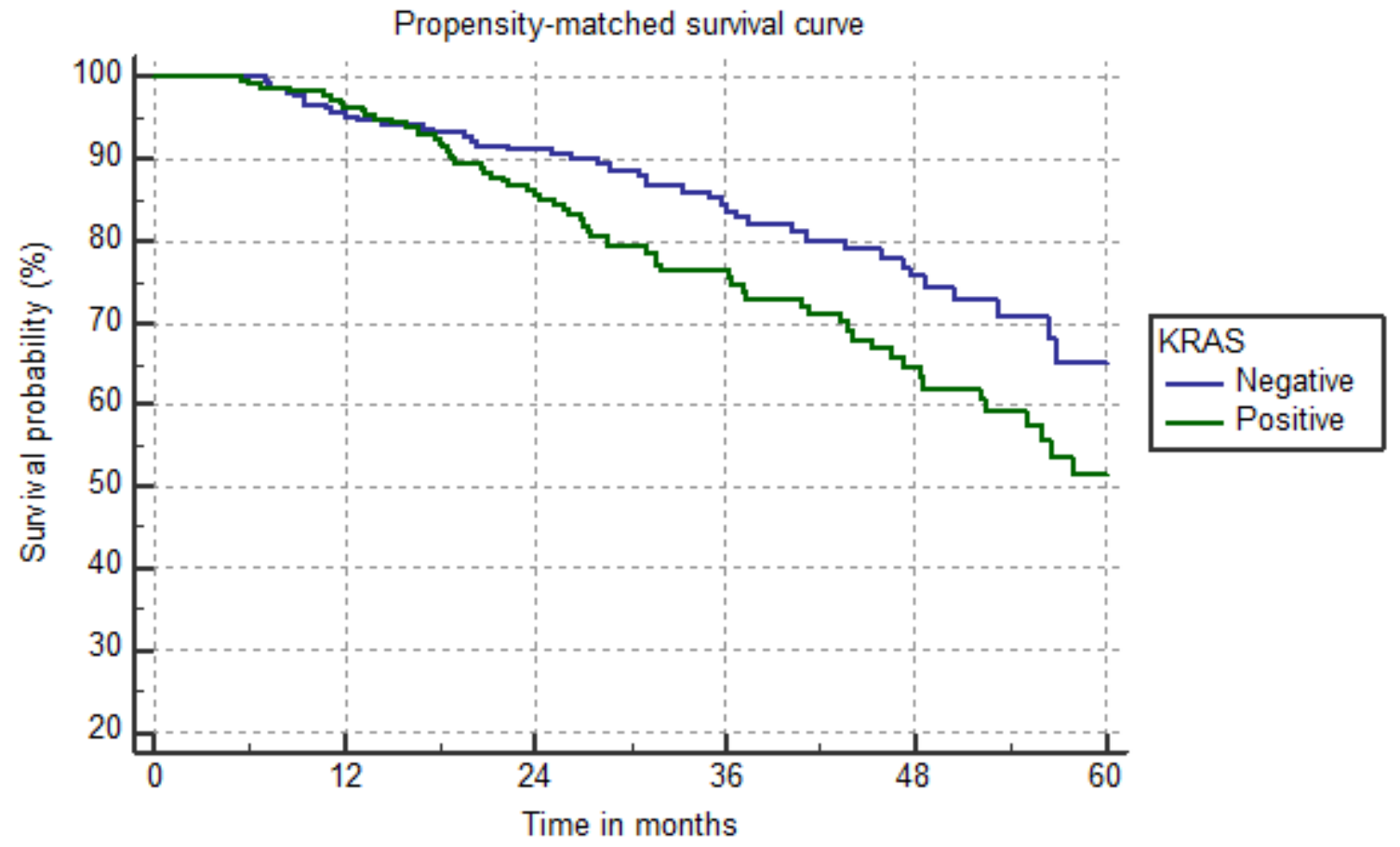

Number at risk

Group: Negative 207

Group: Positive

215

195

159

104

65

21

204

148

92

53

21

Figure 2

Survival by KRAS status 